\title{
Deregulation of inflammatory response in the diabetic condition is associated with increased ischemic brain injury
}

\author{
Eunhee Kim ${ }^{1,2}$, Aaron T Tolhurst ${ }^{1}$ and Sunghee Cho $^{1,2^{*}}$
}

\begin{abstract}
Background: Although elicited inflammation contributes to tissue injury, a certain level of inflammation is necessary for subsequent tissue repair/remodeling. Diabetes, a chronic low-grade inflammatory state, is a predisposing risk factor for stroke. The condition is associated with delayed wound healing, presumably due to disrupted inflammatory responses. With inclusion of the diabetic condition in an experimental animal model of stroke, this study investigates whether the condition alters inflammatory response and influences stroke-induced brain injury.

Methods: C57BL/6 mice were fed a diabetic diet (DD) for 8 weeks to induce an experimental diabetic condition or a normal diet (ND) for the same duration. Gene expression of inflammatory factors including monocyte chemoattractant protein-1 (MCP-1), interleukin-6 (IL-6), CCR2, and CD36 was assessed in the peripheral immune cells and brains of normal and diabetic mice before and after focal cerebral ischemia. The expression of these factors was also determined in lipopolysaccharide (LPS)-treated cultured normal and diabetic macrophages. Ischemic outcome was assessed in these mice at 3 days post-ischemia.

Results: DD intervention in mice resulted in obesity and elevated insulin and glucose level in the blood. The peritoneal immune cells from the diabetic mice showed higher MCP-1 mRNA levels before and after stroke. Compared to normal mice, diabetic mice showed reduced MCP-1, IL-6, and CCR2 gene expression in the brain at $6 \mathrm{~h}$ post-ischemia. LPS-stimulated inflammatory responses were also reduced in the diabetic macrophages. The diabetic mice showed larger infarct size and percent swelling.

Conclusions: These results showed that diabetic conditions deregulate acute inflammatory response and that the condition is associated with increased stroke-induced injury. The study suggests that interventions aimed at restoring appropriate inflammatory response in peripheral immune cells/macrophages may be beneficial in reducing stroke-induced brain injury in subjects with chronic inflammatory conditions.
\end{abstract}

Keywords: Diabetes, Inflammation, Monocytes/macrophages, Ischemic stroke, Mice

\section{Background}

In response to injury, inflammatory responses occur in a rapid and orchestrated manner, involving the innate immune system [1]. While the elicited response by mononuclear cells including monocytes/macrophages contributes to stroke-induced brain injury, an optimal level of acute inflammation by these immune cells is necessary for subsequent resolution of the inflammation

\footnotetext{
* Correspondence: suc2002@med.cornell.edu

'Burke-Cornell Medical Research Institute, White Plains, NY 10605, USA ${ }^{2}$ Brain \& Mind Research Institute, Weill Cornell Medical College at Burke Medical Research Institute, 785 Mamaroneck Ave, White Plains, NY 10605, USA
}

and tissue repair/remodeling. Aberrant activation of these cells has been implicated in the development of age-related diseases and chronic inflammatory conditions [2,3], suggesting the importance of mounting proper acute inflammatory responses following insults.

Studies indicate that the extent of stroke-induced brain injury is influenced by the periphery. It has been shown that increased peripheral inflammation at the time of stroke aggravates ischemic injury [4]. Furthermore, exacerbated ischemic brain injury was reported in mice with elevated levels of plasma cholesterols [5]. The impact of comorbidity on stroke outcome therefore suggests the 
need to include comorbid conditions in the experimental animal model of stroke for a better understanding of pathology and therapeutic strategy.

Diabetes is a predisposing risk factor for cerebrovascular diseases and increases stroke incidence. The prevalent form of diabetes in the human population is type II, which accounts for approximately $90 \%$ of diabetic patients. It has been reported that $70 \%$ of stroke patients were previously diagnosed with diabetes, occult diabetes, or pre-diabetes [6]. Several clinical studies indicated that patients with diabetes had poorer ischemic outcomes [7-11].

The diabetic condition is a chronic systemic low-grade inflammation accompanied by hyperglycemia, glucose intolerance, and hyperinsulinemia [12]. Several proinflammatory proteins including monocyte chemoattractant protein-1 (MCP-1) and interleukin-6 (IL-6) are elevated in the plasma of diabetic patients $[13,14]$. As a major chemokine, MCP-1 plays a role in recruiting macrophages into adipose tissue and causing insulin resistance. The critical role of MCP-1 in the diabetic condition has been demonstrated in studies showing that its overexpression in adipocytes leads to tissue inflammation and insulin resistance, while the mouse deficient in MCP-1 or its receptor, CCR2, reverses the condition [15-17]. In addition, administration of MCP-1 in circulation elicits systemic insulin resistance [18]. Studies also indicate that diabetic conditions increase the burden of CD36 ligands via modifications of low-density lipoprotein (LDL) and excess advanced glycated end products, and augment CD36 expression. CD36 expression is increased in monocytes from type II diabetic patients and in diabetic mouse hearts, suggesting that CD36 expression is modulated by the diabetic condition [19-22].

Despite the increasing incidence of type II diabetes [12], relatively few investigations of stroke injury have been performed in animal models that closely mimic human type II diabetes. To be clinically relevant, the current study established diet-induced type II diabetes in C57BL/6 mice. Using this experimental mouse model of diabetes, this study investigates the effect of the diabetic condition on stroke-induced inflammatory response and brain injury. We report that in the diabetic condition, acute inflammatory responses are perturbed in the brain following stroke and in the macrophages after lipopolysaccharide (LPS) stimulation, and the alteration is associated with the exacerbation of stroke-induced injury.

\section{Methods}

\section{Animals and diets}

The use of animals and the procedures were approved by the Institutional Animal Care and Use Committee of Weill Medical College of Cornell University. Experiments were performed in male C57BL/6 mice. Six-week-old C57BL/6 mice were fed either a normal diet (ND, $4.5 \%$ fat and
53.0\% carbohydrate, 5053, LabDiet, MO, USA) or a diabetogenic diet (DD, 36\% fat and 35.7\% carbohydrate, F3282, Bioserv, NJ, USA) for 8 weeks to induce the diabetic condition. Individuals who performed tissue cutting and gene analysis were blinded to the animal's identity. The code was revealed after data were collected.

\section{Plasma glucose measurement and glucose tolerance test (GTT)}

To monitor the progression of the diabetic condition, weight and fasting plasma glucose levels were measured and GTT was performed after 7 weeks of diet. Blood glucose levels were measured from a tail snip of the overnight fasted ND and DD fed mice using a glucometer (Ascensia Contour, Bayer, Germany). For GTT, the overnight fasted mice were injected intraperitoneally with $2 \mathrm{~g} / \mathrm{kg}$ of D-glucose and blood glucose levels were measured at 15, 45, and 120 min post-injection.

\section{Plasma MCP-1 and insulin measurement}

Plasma MCP-1 and insulin levels were determined using commercially available kits (MCP-1 ELISA kit, R\&D systems, MN, USA; insulin EIA kit, ALPCO Diagnostics, $\mathrm{NH}$, USA) according to the manufacturers' procedures. For MCP-1, mouse trunk blood was collected in a heparinized tube. For insulin, the mice were overnight-fasted and then blood was collected from the tail vein. The collected blood was centrifuged at 3,000 rpm for $10 \mathrm{~min}$ and the plasma was stored at $-80^{\circ} \mathrm{C}$ until analysis.

\section{Harvesting peritoneal cells and primary macrophage culture}

The peritoneal cavity of normal and diabetic mice was filled with sterile phosphate buffered saline (PBS), gently massaged, and the PBS was withdrawn. The peritoneal lavage was repeated 3 to 4 times and the collected solution was centrifuged at $3,000 \mathrm{rpm}$ for $10 \mathrm{~min}$. The cell pellet was stored at $-80^{\circ} \mathrm{C}$ until total RNA extraction. Primary macrophages were cultures by a modified method from previous studies [23-25]. The peritoneal cells obtained by lavage were suspended in macrophage serum-free media (MSF, Invitrogen, Carlsbad, CA, USA) containing $1 \%$ penicillin/streptomycin (Sigma, St Louis, MO, USA). The re-suspended cells were plated in a 12-well cell culture dish $\left(2 \times 10^{6}\right.$ cells/well $)$ and incubated overnight at $37^{\circ} \mathrm{C}$ with $5 \% \mathrm{CO}_{2}$. The adhered cells on the plate were washed with sterile PBS, incubated in the MSF for $1 \mathrm{~h}$, and then treated with $0.2 \mu \mathrm{g} / \mathrm{mL}$ LPS for $6 \mathrm{~h}$. Total RNA was extracted from the LPS-treated cells for gene expression analysis.

\section{Flow cytometry analysis}

Flow cytometry analysis was performed in peritoneal immune cells according to the methods previously described 
[26-28]. After blocking in 10\% FBS for $1 \mathrm{~h}$, the peritoneal cells were incubated with allophycocyanin-conjugated antibody against myeloid cells including monocyte/macrophages (CD11b, Clone M1/7) and a cocktail of phycoery thrin-conjugated antibodies (BD Biosciences, San Jose, CA, USA) against T cells (CD90.2, Clone 53-2.1), B cells (CD45R/B220, Clone RA3-6B2), NK cells (CD49b/PanNK cells, Clone DX5; NK1.1, Clone PK136), and granulocytes (Ly-6G, Clone 1A8) in 1\% FBS. Cells were washed with PBS and passed through a $40-\mu \mathrm{m}$ cell strainer prior to flow cytometry analysis (Accuri C6, BD Bioscience).

\section{Transient middle cerebral artery occlusion (MCAO)}

The normal and diabetic mice were subjected to MCAO according to the method previously described $[5,29]$. Mice were anesthetized with isoflurane (1.5\% to $2.0 \%)$ with a mixture of oxygen and nitrogen (30\%/70\%). A fiber optic probe was glued to the parietal bone $(2 \mathrm{~mm}$ posterior and $5 \mathrm{~mm}$ lateral to the bregma) and connected to a Laser-Doppler Flowmeter (Periflux System 5010; Perimed, Järfälla, Sweden) for continuous monitoring of cerebral blood flow in the center of the ischemic territory. A 6-0 Teflon-coated black monofilament surgical suture (Doccol Co., Redland, CA, USA) was inserted into the exposed external carotid artery, advanced into the internal carotid artery, and wedged into the cerebral arterial circle to obstruct the origin of the MCA for $30 \mathrm{~min}$. The filament was withdrawn to allow reperfusion. Using a rectal probe controlled by a Masterflex pump and thermistor temperature controller (Cole-Parmer, Vernon Hills, IL, USA), the animals' body temperatures were maintained at $37 \pm 0.5^{\circ} \mathrm{C}$ during $\mathrm{MCAO}$ and $1 \mathrm{~h}$ post-ischemia.

Tissue section strategy for infarct volume, swelling, and gene expression measurement

To obtain tissue that contains the entire infarct territory, an unbiased stereological sampling strategy was used according to the method described in the previous study [29]. Three days after MCAO, brains were excised, frozen, and serial sections spanning about $6 \mathrm{~mm}$ rostrocaudal (roughly $+2.8 \mathrm{~mm}$ and extending to $-3.8 \mathrm{~mm}$ from bregma) were collected. The entire infarct region was cryosectioned for infarct volume measurement $(20 \mu \mathrm{m}$ thickness) and collected serially at $600 \mu \mathrm{m}$ intervals. Infarct volume and hemispheric swelling were measured using Axiovision software (Zeiss, Germany). Infarct volume was corrected for swelling by a method described previously [30]. Tissues between the $600 \mu \mathrm{m}$ intervals were sectioned and cut in half and collected for each hemisphere to determine mRNA levels.

\section{RNA extraction and gene expression analysis}

Total RNA was extracted using RNeasy mini extraction kit (Qiagen, Valencia, CA, USA) for cultured peritoneal macrophages or Tri reagent (MRC, OH, USA) for brain tissues. Total RNA was reverse-transcribed using oligo (dT) primers and the SuperScript First-Strand Synthesis System (Invitrogen) according to the manufacturer's protocol. PCR primers and probes specific for MCP-1, IL-6, CCR2, CD36, and $\beta$-actin (an internal control) were obtained as TaqMan pre-developed optimized assay reagents for gene expression (Applied Biosystems, Foster City, CA, USA). The PCR reaction was performed using TaqMan Universal PCR Mastermix, No AmpErase UNG, and 7500 Fast Real-Time PCR system (Applied Biosystems) according to the manufacturer's protocol. Reactions were performed in $20 \mu \mathrm{L}$ total volume and incubated at $95^{\circ} \mathrm{C}$ for $10 \mathrm{~min}$, followed by 40 cycles of $15 \mathrm{sec}$ at $95^{\circ} \mathrm{C}$, and $1 \mathrm{~min}$ at $60^{\circ} \mathrm{C}$. The results were analyzed by 7500 Fast Real-Time PCR System software (Applied Biosystems).

\section{Data analysis}

Infarct volume and percent hemispheric swelling were reported as mean $\pm 95 \%$ confidence interval $(\mathrm{CI})$. Gene and protein levels were reported as mean \pm SEM. Gene expression levels from in vivo studies were presented as the $\beta$-actin normalized value according to the formula, value $=2^{\text {(Ct } \text { of } \beta \text {-actin-Ct of target gene) }}$. Gene expression levels in in vitro studies were reported relative to control cultures and averaged from two independent experiments. Comparison between the two groups was statistically evaluated using Student's $t$-test. Differences were considered significant at $P<0.05$.

\section{Results}

\section{Characterization of experimental mouse model of type II diabetes}

Mice fed a DD gained body weight significantly faster than those fed a ND (Figure 1A). The DD also caused significantly higher plasma insulin levels measured after 7 weeks of diet (Figure 1B). DD mice displayed elevated blood glucose levels (ND vs. DD, $115.4 \pm 11.5$ vs. $180.7 \pm 9.3$, $\mathrm{n}=15$ /group, $P<0.001)$. Upon glucose challenge, the mice fed a DD showed slower glucose clearance, suggesting the development of insulin resistance (Figure 1C). MCP-1 levels in the plasma of DD mice were significantly higher than that of ND mice (Figure 1D). The results showed that DD intervention induces hallmarks of type II diabetes in mice.

\section{Elevated MCP-1 expression in diabetic peritoneal cells}

The peritoneal cavity harbors resident immune cells including lymphocytes and macrophages. FACS analysis of the peritoneal immune cells using antibodies against CD11b (monoctyes/macrophages) and Lin, an antibody cocktail for lineage markers (lymphocytes, NK cells, and granulocytes) showed that several populations and approximately $20 \%$ of cells represent monocytes/macrophages 


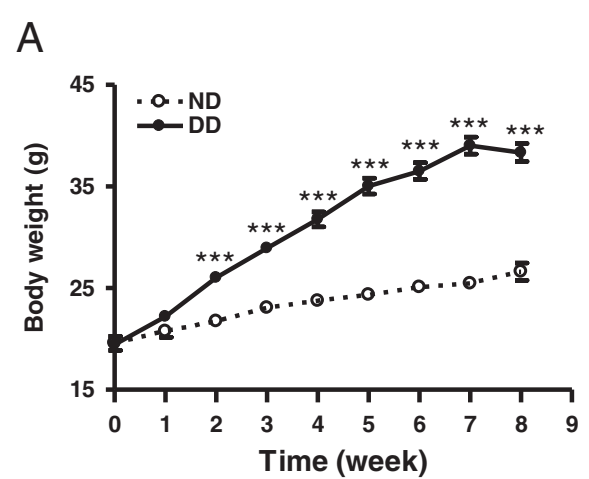

B
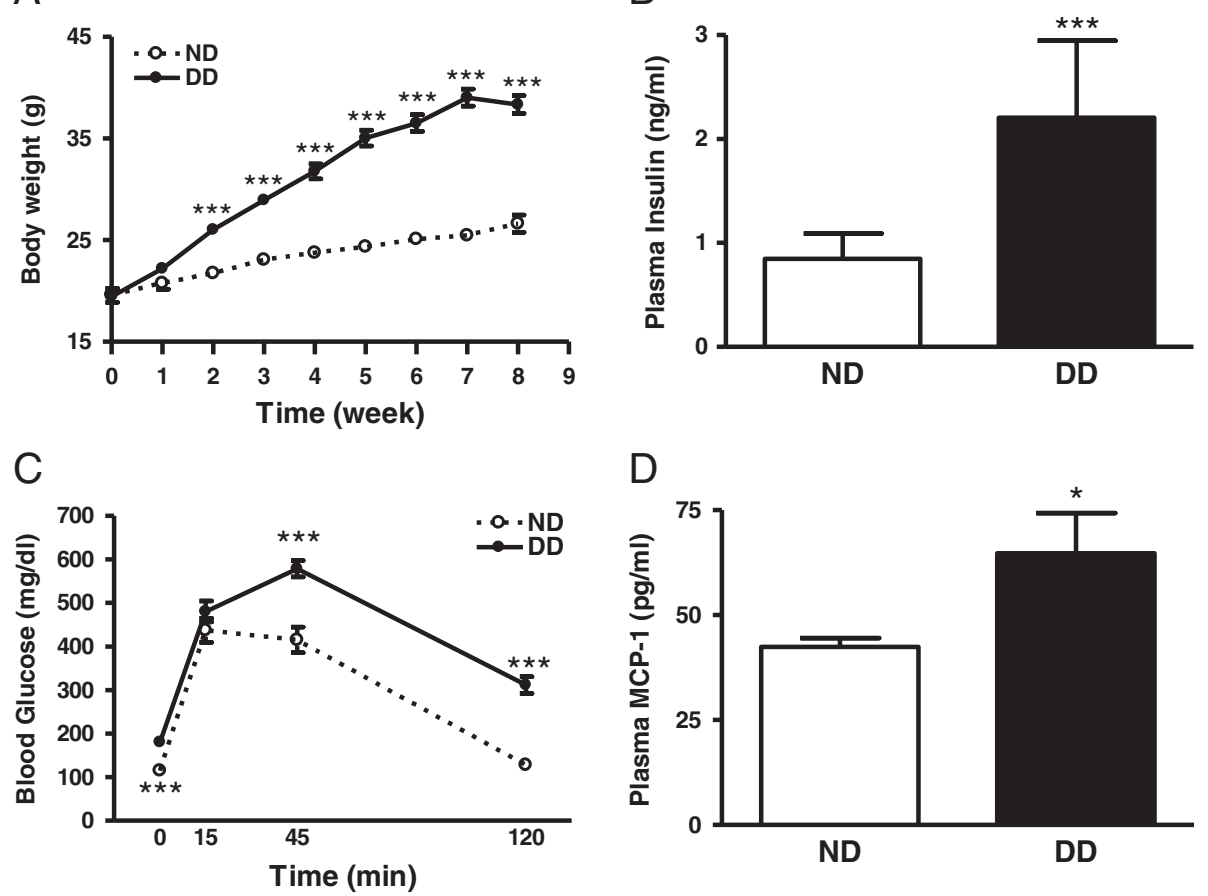

D

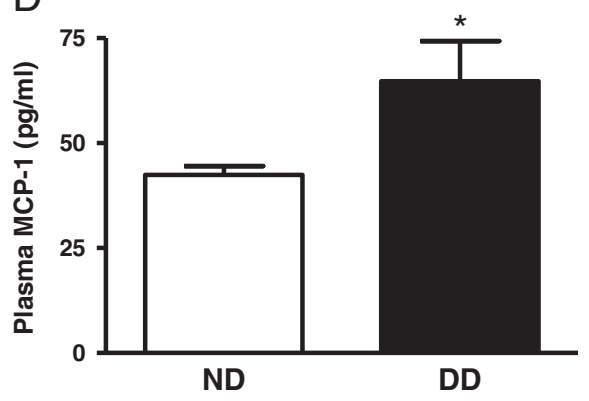

Figure 1 Characterization of diet-induced diabetic mouse model. (A) Body weight changes during 8 weeks of diet intervention, $n=14$ to 15/group. (B) Plasma insulin levels, $n=11$ to 14/group. (C) Clearance of blood glucose upon glucose challenge by glucose tolerance test, $n=15 /$ group, (D) Plasma MCP-1 levels, $n=5$ /group. ND, normal diet; DD, diabetic diet; ${ }^{*} P<0.05,{ }^{* * *} P<0.001$ vs. ND.

$\left(\right.$ Lin $\left.^{\text {low }} / \mathrm{CD} 11 \mathrm{~b}^{\text {high }}\right)$ (Figure $\left.2 \mathrm{~A}\right)$. We determined the expression of several inflammatory genes in these resident peritoneal immune cells obtained from normal and diabetic mice. Prior to stroke, the basal MCP-1 gene expression in the diabetic peritoneal cells was highly elevated (Figure 2B) while IL-1 $\beta$ and TNF $\alpha$ were not different between normal and diabetic peritoneal cells (data not shown). Additionally, we did not find differences between the groups in other inflammatory mediators including IL-6, CCR2, and CD36 (Figure 2C-E). Stroke induced an increase in MCP-1 at $6 \mathrm{~h}$ and $72 \mathrm{~h}$ after ischemia in the diabetic peritoneal cells (Figure 2B), while IL-6, CCR2, and CD36 gene expressions were not different between the normal and diabetic cells (Figure 2C-E). The results showed selective and sustained elevation of MCP-1 in the diabetic peritoneal cells.

\section{The compromised acute inflammatory response in the stroked brain}

We next investigated stroke-induced inflammatory response in the normal and diabetic brain. Compared to that of normal mice, basal gene expression before stroke in the brain of diabetic mice showed lower CD36 $\left(\times 10^{-4}\right)$ (ND vs. $\mathrm{DD}, 6.9 \pm 0.6$ vs. $5.2 \pm 0.3, \mathrm{n}=4$ to 5/group, $P<0.05)$, while MCP-1, IL-6, and CCR2 were similar between the groups (ND vs. DD, MCP-1 $\left(\times 10^{-5}\right), 6.3 \pm 0.3$ vs. $6.2 \pm 0.5$; IL- $6\left(\times 10^{-5}\right), 4.9 \pm 0.2$ vs. $5.4 \pm 0.4$; and CCR2 $\left(\times 10^{-5}\right), 2.9 \pm 0.5$ vs. $\left.3.4 \pm 0.3\right)$.
Gene expression in the brain prior to stroke and in the contralateral hemisphere following stroke was relatively unchanged (data not shown). There was, however, a profound increase in the ipsilateral brain. MCP-1 expression increased $>50$-fold in the normal brains at $6 \mathrm{~h}$; the fold induction at this time point was significantly attenuated in the diabetic brains (Figure 3B). This early-blunted inflammatory response at $6 \mathrm{~h}$ in the diabetic brain was also observed in the expression of IL- 6 and CCR2, a receptor for MCP-1 (Figure 3C and D). The differences, however, were not observed at $72 \mathrm{~h}$ post-ischemia except in CD36, which showed increased expression in the diabetic brain (Figure 3E). Collectively, the data suggest that early inflammatory responses in the diabetic brain are deregulated.

\section{Attenuated LPS-stimulated inflammatory response in diabetic macrophages}

Mononuclear cells including monocytes/macrophages that infiltrate into infarct, contribute to inflammation in the injured tissue. We therefore investigated whether these immune cells largely account for the blunted inflammatory response upon insults, as we observed in the stroked brain. Primary macrophages from the normal and diabetic mice were cultured and their responses to external inflammatory stimulus were investigated. Compared to vehicle-treated cultures, LPS increased MCP-1 
A

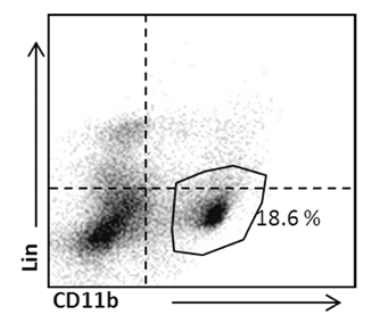

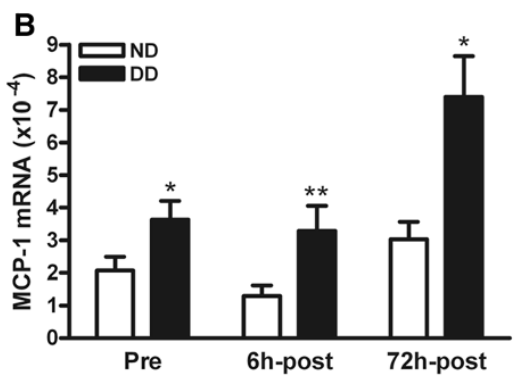

E

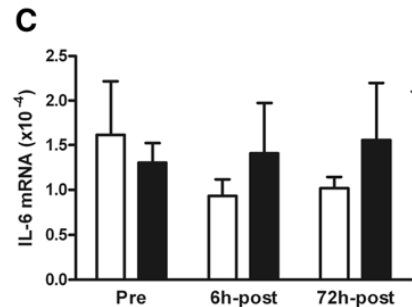

D
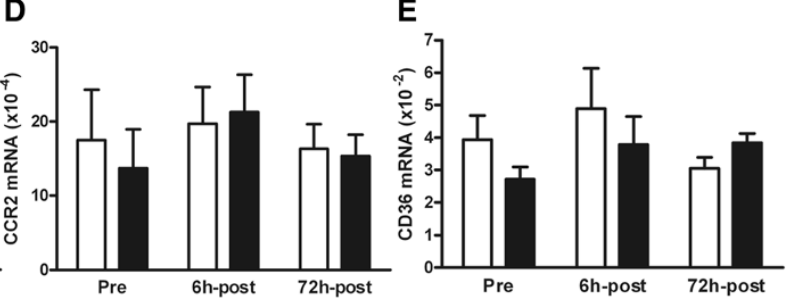

Figure 2 Effect of the diabetic condition on inflammatory gene expression in the peritoneal cells before and after stroke. (A) Flow cytometry analysis of peritoneal immune cells. The cells in the gated area indicate CD $11 \mathrm{~b}^{+} / \mathrm{Lin}^{-}\left(\mathrm{CD} 11 \mathrm{~b}^{\text {high }} / \mathrm{Lin}^{\text {low }}\right.$ ) monocytes/macrophages. (B to E) Gene expression of MCP-1 (B), IL-6 (C), CCR2 (D), and CD36 (E) in normal and diabetic peritoneal cells prior to ischemia (pre-) and at $6 \mathrm{~h}$ (6 h-post) and $72 \mathrm{~h}$ after stroke (72 h-post), $\mathrm{n}=9$ to 13/group. ND, normal mice; DD, diabetic mice; Lin, markers for lymphocytes/NK cells/granulocytes; CD1 1b, a marker for mononuclear phagocytes; ${ }^{*} P<0.05,{ }^{* *} P<0.01$ vs. ND.

and IL-6 expression in normal macrophages. However, the responses to LPS were significantly attenuated in diabetic macrophages (Figure 4A and B), showing altered chemokine and cytokine expression in LPS-stimulated diabetic macrophages. CCR2 and CD36 gene expression was higher in the vehicle-treated diabetic macrophages; LPS down-regulated CCR2 and CD36 expression in both normal and diabetic macrophages (Figure $4 \mathrm{C}$ and D). The results suggest that diabetic macrophages exhibit altered responses upon an external inflammatory stimulus.

\section{Exacerbation of ischemic brain injury in the DD mice}

The effect of diabetes on ischemic outcome was assessed. Histological examination at 3 days after stroke revealed that the diabetic mice showed an increased infarct size and percent hemispheric swelling (Figure 5A-C). To determine the contribution of hemispheric swelling, we further performed correlation analyses within the groups. Infarct size is positively correlated with percent swelling in normal mice $\left(r^{2}=0.5089, P<0.001\right)$. However, there is no correlation between infarct size and percent swelling in diabetic mice $\left(r^{2}=0.03895\right.$, ns). In addition, the correlation slopes between the groups were significantly different $(P=0.0113)$, showing a larger swelling component at a given infarct in the diabetic mice. The result indicates that differential dynamics in acute infarct evolution in diabetic mice may contribute to the exacerbation of stroke induced brain injury (Figure 5D).

\section{Discussion}

Accumulating evidence suggests that peripheral status influences stroke-induced brain injury, a major CNS event. With the inclusion of the diabetic condition in an experimental animal model of stroke, the current study addresses the effect of the condition on stroke-induced inflammatory response and outcome. An important finding of this study is that the diet-induced diabetic condition captures many features of prevalent type II diabetes, evidenced by obesity, increased plasma insulin and MCP-1 protein, as well as the development of insulin resistance. In the diabetic mice, stroke-induced inflammatory response in the brain was blunted. Moreover, diabetic macrophages also displayed attenuated expression of pro-inflammatory chemokines and cytokines in response to LPS stimulation. The altered acute inflammatory response in diabetic conditions is associated with the exacerbation of stroke injury, implying the importance of mounting the proper inflammatory response in limiting stroke-induced brain injury in the presence of the comorbidity.

The diet-induced obese mice used in the current study provide a suitable experimental model to investigate the impact of the diabetes comorbidity in stroke. In contrast to the widely used genetically modified ob/ob or $\mathrm{db} / \mathrm{db}$ mice that display excessively elevated fasting blood glucose (190 to $400 \mathrm{mg} / \mathrm{dL}$ ) and plasma insulin levels (20-fold) [31-33], the current model displays obesity, moderately increased insulin and fasting blood glucose, 

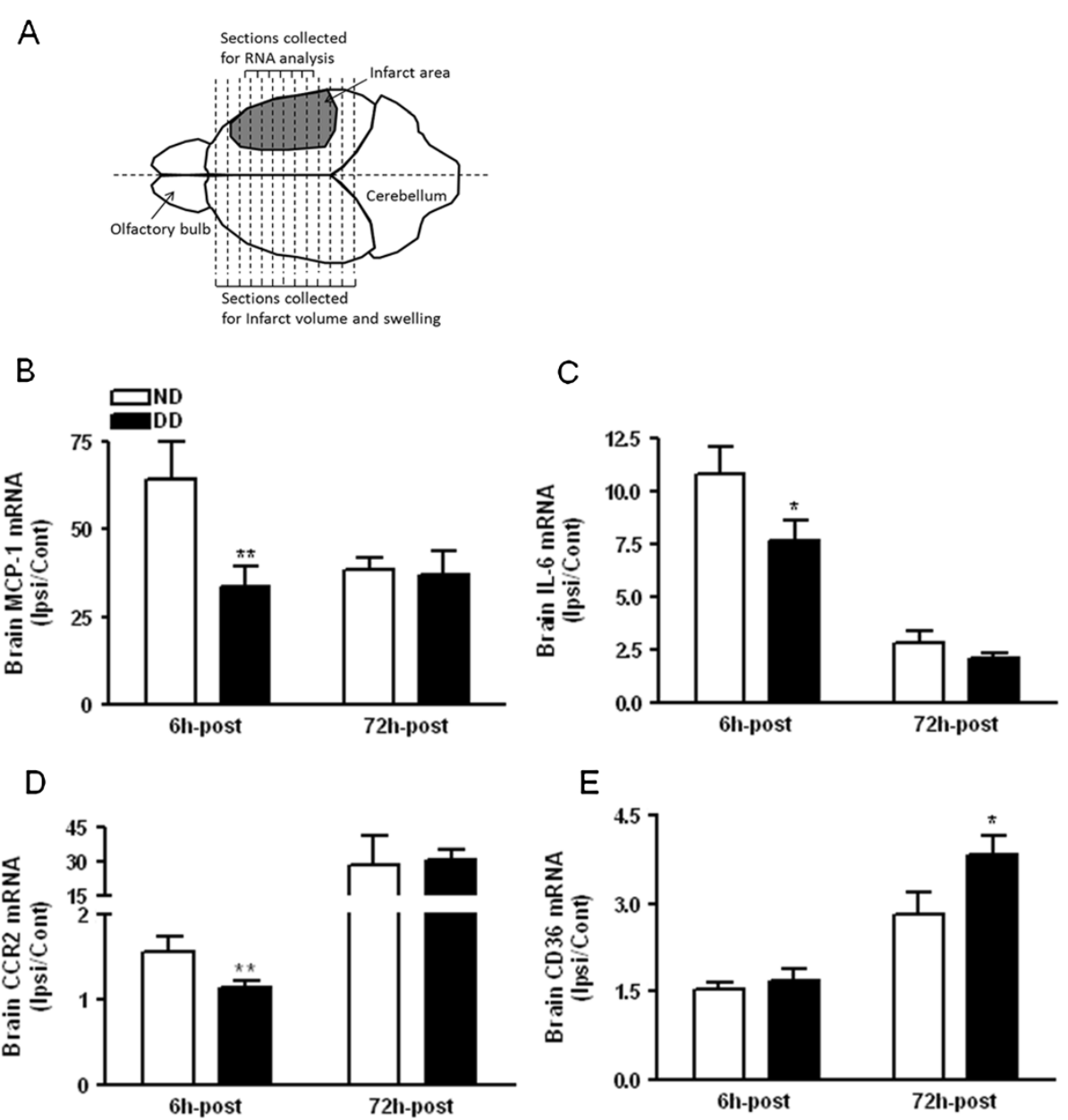

Figure 3 Effect of the diabetic condition on inflammatory gene expression in the post-ischemic brain. (A) A diagram for unbiased tissue sampling strategy. (B to E) Gene expressions of MCP-1 (B), IL-6 (C), CCR2 (D), and CD36 (E) in the brain at $6 \mathrm{~h}(\mathrm{n}=9$ to 12$)$ and $72 \mathrm{~h}(\mathrm{n}=4$ to 5$)$ after stroke. ND, normal mice; DD, diabetic mice. Data were expressed as fold induction in the ipsilateral hemisphere relative to contralateral side (Ipsi/Cont); ${ }^{*} P<0.05,{ }^{* *} P<0.01$ vs. ND.

insulin resistance, and increased $\mathrm{MCP}-1$ in the plasma and peritoneal immune cells (Figures 1 and 2). These hallmarks of type II diabetes featured in the current model signify its validity and advantage over genetic models in studying the effect of diabetes in stroke pathology and outcome.

Hyperglycemia-induced acidosis with lactate buildup was considered a potential mechanism by which diabetic conditions exacerbate stroke-induced brain injury [34-36]. However, arguments against this view include a study that showed greater injury size in diabetic mice than in control mice despite comparable plasma glucose levels [37,38]. Moreover, a report on larger infarct size with lower glucose and lactoacidosis in male $\mathrm{db} / \mathrm{db}$ mice compared to female mice [39], further supports the view that hyperglycemia, per se, may not account for the diabetesinduced aggravation of stroke injury.
Chronic inflammation is a salient feature of metabolic disorders and aging-related disease. Because the chronic inflammation is associated with compromised antimicrobial defenses, delayed wound healing, and impaired inflammatory responses $[2,40]$, immunological disturbances may be an underlying event for diabetes-induced exacerbation of ischemic brain injury. Diabetic mice $(d b / d b)$ displayed reduced inflammatory cytokine expression and microglial activation and delayed wound healing [41]. Since microglial activation and the release of chemokines and cytokines are critical steps in eliciting inflammatory response, we speculate that inability to mount a proper host immune response immediately after cerebral ischemia in diabetic microglia may cause an extended inflammatory phase, which leads to a prolonged infiltration of peripheral immune cells and worsen ischemic injury. Sustained elevation of glucose has been linked to 


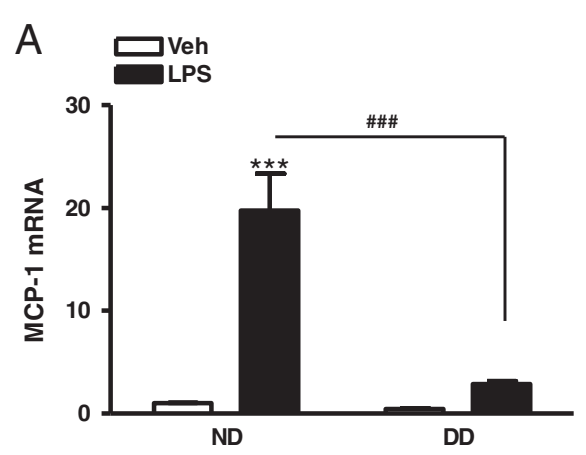

B
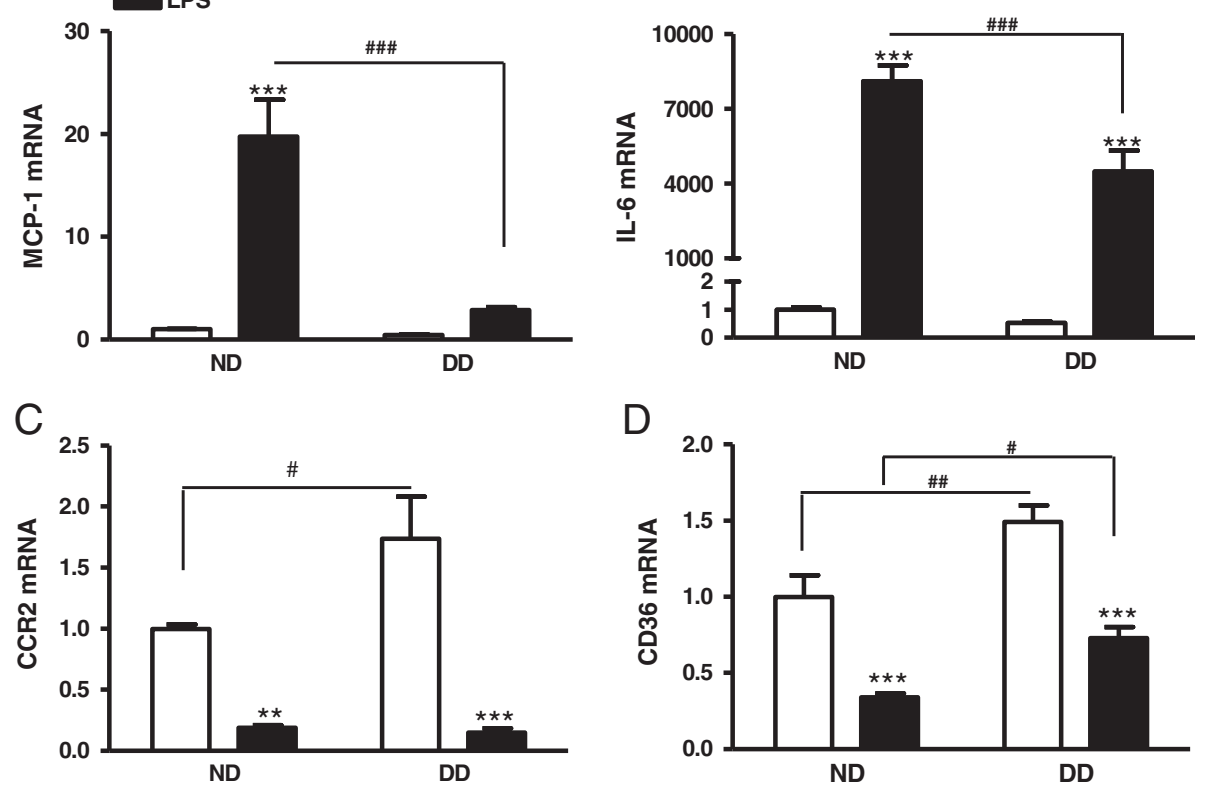

Figure 4 Deregulated inflammatory response in LPS-stimulated diabetic macrophages. Gene expression of MCP-1 (A), IL-6 (B), CCR2 (C), and CD36 (D) in primary macrophages in the absence and presence of LPS. ND, macrophages from the mice fed a normal diet $(n=9) ; D D$, macrophages from the mice fed a diabetic diet $(n=10)$. Data were expressed as fold difference compared to vehicle treated ND macrophages. ${ }^{* *} P<0.01,{ }^{* * *} P<0.001$ vs. vehicle; ${ }^{\#} P<0.05,{ }^{\# \#} P<0.01,{ }^{\# \#} P<0.001$ vs. ND; two way ANOVA with a post-hoc Bonferroni test.

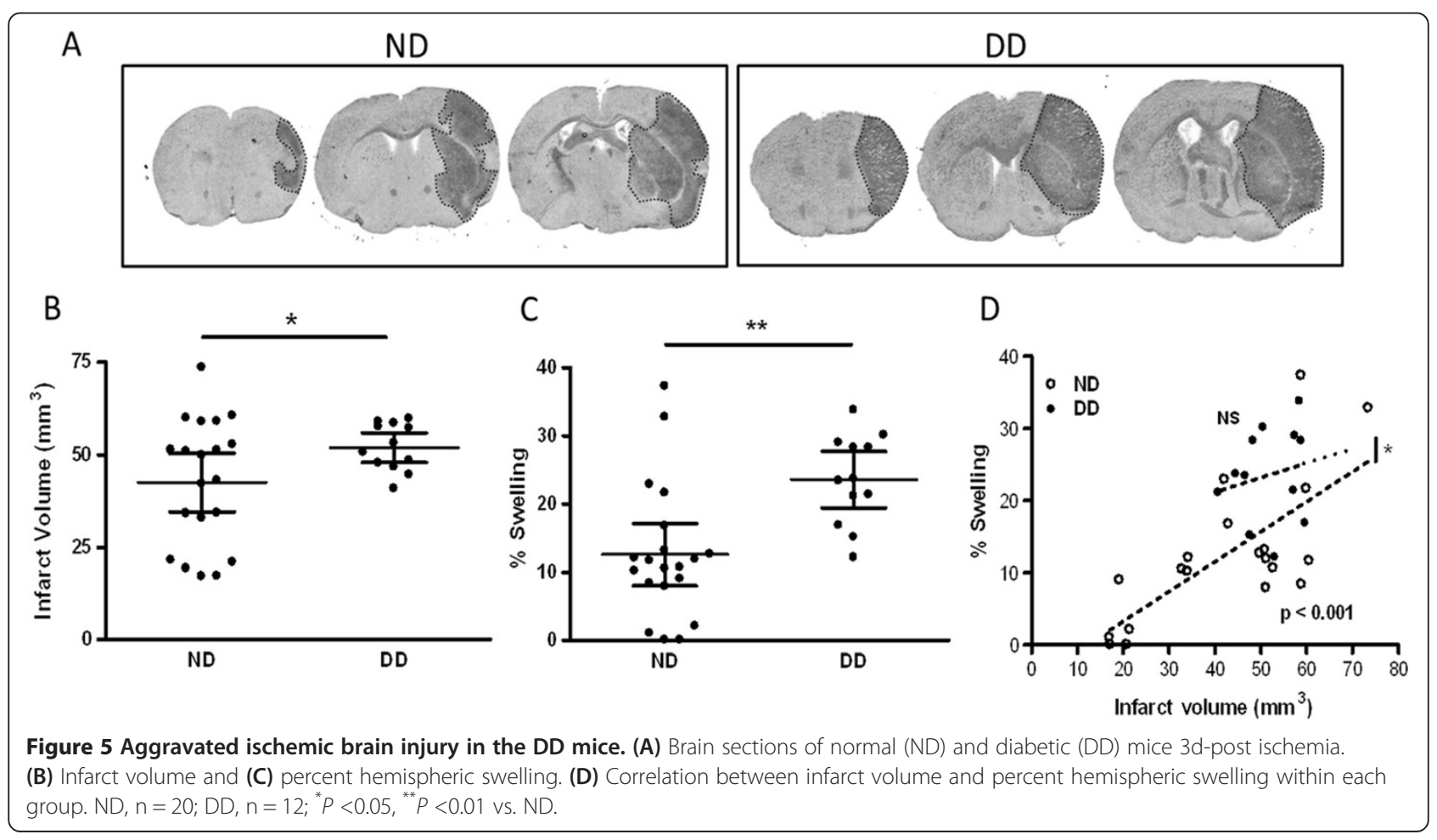


dysregulation of normal immune function through Ctype lectin-mediated immune function [42]. Our finding of attenuated stroke-induced inflammatory response in diabetic mice is also consistent with literature showing attenuated LPS-stimulated IL-6 levels and hypoxic/ischemia-induced cytokine in diabetic conditions [41,43-45]. Besides its implicated role as a prototype inflammatory receptor in acute cerebral ischemia [5,29,46], CD36 in the plasma was identified as a novel marker of insulin resistance [21,47]. Increased CD36 expression in the ischemic brains and diabetic macrophages in this study may reflect the feed-forward expression of CD36 in the presence of excess CD36 ligands such as advanced glycated end products and glucose-oxidized LDL in the diabetic condition.

Although stroke-induced MCP-1 expression suggests its role in the trafficking of inflammatory immune cells to the injury site, the attenuated MCP-1 expression in the diabetic brain following stroke (Figure 3 ) suggests a perturbed immune response. In age-related chronic inflammatory conditions, several functions of mononuclear phagocytes, including immune defense, inflammation, and phagocytosis, are deregulated [40]. In the current study, the reduced LPS-stimulated MCP-1 and IL-6 expression in the diabetic macrophages (Figure 4) provided a mechanistic link between impaired mononuclear phagocyte function and diabetes-induced exacerbation of ischemic injury. Despite the impaired pro-inflammatory MCP-1 and IL-6 in the ischemic brain and LPS-stimulated macrophages, increased stroke-induced brain injury in diabetic conditions suggests a benefit of rapid inflammatory response following stroke. This may be relevant to the reported protective role of MCP-1 against apoptotic stimuli and excitotoxicity in neurons [48,49], norepinephrineinduced reduction of neuronal damage [50], and wound healing [51,52].

\section{Conclusions}

In summary, we report that disturbed immune response in diabetic mice is associated with increased strokeinduced brain injury. The study showed that impaired inflammatory function in mononuclear cells and inability to elicit rapid inflammatory responses may partly underlie the diabetes-induced exacerbation of stroke injury. As tissue injury typically elicits a rapid inflammatory response to resolve inflammation, this study indicates the importance of mounting timely inflammatory responses to limit stroke-induced injury in subjects with chronic systemic inflammatory conditions. Careful and discriminatory blockade of inflammation should be cautiously considered for stroke therapies.

\section{Abbreviations}

DD: Diabetogenic diet; ND: Normal diet; GTT: Glucose tolerance test; IL-6: Interleukin-6; LDL: Low-density lipoprotein; LPS: Lipopolysaccharide;
MCAO: Middle cerebral artery occlusion; MCP-1: Monocyte chemoattractant protein-1.

\section{Competing interests}

We do not have competing interests.

\section{Author's contributions}

EK designed the experiments, established the diabetic mouse model, performed biochemical and molecular assays, performed data analysis, and wrote the manuscript. ATT generated the mouse model of ischemia and assessed stroke outcome. SC directed the overall study design, analyzed the data, and finalized the manuscript. All authors have read and approved the final manuscript.

\section{Acknowledgements}

This work was supported by the NIH award NS07789, HL082511 (S.C.), and the Burke Foundation.

Received: 4 February 2014 Accepted: 26 March 2014

Published: 1 May 2014

\section{References}

1. Barton GM: A calculated response: control of inflammation by the innate immune system. J Clin Invest 2008, 118:413-420.

2. Hearps AC, Martin GE, Angelovich TA, Cheng WJ, Maisa A, Landay AL, Jaworowski A, Crowe SM: Aging is associated with chronic innate immune activation and dysregulation of monocyte phenotype and function. Aging Cell 2012, 11:867-875.

3. Graves DT, Kayal RA: Diabetic complications and dysregulated innate immunity. Front Biosci 2008, 13:1227-1239.

4. McColl BW, Rothwell NJ, Allan SM: Systemic inflammatory stimulus potentiates the acute phase and CXC chemokine responses to experimental stroke and exacerbates brain damage via interleukin-1- and neutrophil-dependent mechanisms. J Neurosci 2007, 27:4403-4412.

5. Kim E, Tolhurst AT, Qin LY, Chen XY, Febbraio M, Cho S: CD36/fatty acid translocase, an inflammatory mediator, is involved in hyperlipidemiainduced exacerbation in ischemic brain injury. J Neurosci 2008, 28:4661-4670

6. Kernan WN, Inzucchi SE: Type 2 diabetes mellitus and insulin resistance: stroke prevention and management. Curr Treat Options Neurol 2004, 6:443-450

7. Almdal T, Scharling $H$, Jensen JS, Vestergaard $H$ : The independent effect of type 2 diabetes mellitus on ischemic heart disease, stroke, and death: a population-based study of 13,000 men and women with 20 years of follow-up. Arch Intern Med 2004, 164:1422-1426.

8. Bonow RO, Gheorghiade M: The diabetes epidemic: a national and global crisis. Am J Med 2004, 116(Suppl 5A):2S-10S.

9. Capes SE, Hunt D, Malmberg K, Pathak P, Gerstein HC: Stress hyperglycemia and prognosis of stroke in nondiabetic and diabetic patients: a systematic overview. Stroke 2001, 32:2426-2432.

10. Mankovsky BN, Ziegler D: Stroke in patients with diabetes mellitus. Diabetes Metab Res Rev 2004, 20:268-287.

11. Sundquist $K$, Li X: Type 1 diabetes as a risk factor for stroke in men and women aged 15-49: a nationwide study from Sweden. Diabet Med 2006, 23:1261-1267.

12. Smyth $\mathrm{S}$, Heron A: Diabetes and obesity: the twin epidemics. Nat Med 2006, 12:75-80.

13. Kern PA, Ranganathan S, Li C, Wood L, Ranganathan G: Adipose tissue tumor necrosis factor and interleukin- 6 expression in human obesity and insulin resistance. Am J Physiol Endocrinol Metab 2001, 280:E745-E751.

14. Nomura S, Shouzu A, Omoto S, Nishikawa M, Fukuhara S: Significance of chemokines and activated platelets in patients with diabetes. Clin Exp Immunol 2000, 121:437-443.

15. Kamei N, Tobe K, Suzuki R, Ohsugi M, Watanabe T, Kubota N, OhtsukaKowatari N, Kumagai K, Sakamoto K, Kobayashi M, Yamauchi T, Ueki K, Oishi Y, Nishimura S, Manabe I, Hashimoto H, Ohnishi Y, Ogata H, Tokuyama K, Tsunoda M, Ide T, Murakami K, Nagai R, Kadowaki T: Overexpression of monocyte chemoattractant protein-1 in adipose tissues causes macrophage recruitment and insulin resistance. J Biol Chem 2006, 281:26602-26614.

16. Kanda H, Tateya S, Tamori Y, Kotani K, Hiasa K, Kitazawa R, Kitazawa S, Miyachi H, Maeda S, Egashira K, Kasuga M: MCP-1 contributes to 
macrophage infiltration into adipose tissue, insulin resistance, and hepatic steatosis in obesity. J Clin Invest 2006, 116:1494-1505.

17. Weisberg SP, Hunter D, Huber R, Lemieux J, Slaymaker S, Vaddi K, Charo I, Leibel RL, Ferrante AW Jr: CCR2 modulates inflammatory and metabolic effects of high-fat feeding. J Clin Invest 2006, 116:115-124.

18. Tateya S, Tamori $Y$, Kawaguchi $T$, Kanda $H$, Kasuga M: An increase in the circulating concentration of monocyte chemoattractant protein-1 elicits systemic insulin resistance irrespective of adipose tissue inflammation in mice. Endocrinology 2010, 151:971-979.

19. Greenwalt DE, Scheck SH, Rhinehart-Jones T: Heart CD36 expression is increased in murine models of diabetes and in mice fed a high fat diet. J Clin Invest 1995, 96:1382-1388.

20. Griffin E, Re A, Hamel N, Fu C, Bush H, McCaffrey T, Asch AS: A link between diabetes and atherosclerosis: Glucose regulates expression of CD36 at the level of translation. Nat Med 2001, 7:840-846.

21. Handberg A, Levin K, Hojlund K, Beck-Nielsen H: Identification of the oxidized low-density lipoprotein scavenger receptor CD36 in plasma: a novel marker of insulin resistance. Circulation 2006, 114:1169-1176.

22. Sampson MJ, Davies IR, Braschi S, Ivory K, Hughes DA: Increased expression of a scavenger receptor (CD36) in monocytes from subjects with Type 2 diabetes. Atherosclerosis 2003, 167:129-134.

23. Cho S, Szeto HH, Kim E, Kim H, Tolhurst AT, Pinto JT: A novel cell-permeable antioxidant peptide, SS31, attenuates ischemic brain injury by down-regulating CD36. J Biol Chem 2007, 282:4634-4642.

24. Ding AH, Nathan CF, Stuehr DJ: Release of reactive nitrogen intermediates and reactive oxygen intermediates from mouse peritoneal macrophages. Comparison of activating cytokines and evidence for independent production. J Immunol 1988, 141:2407-2412.

25. Tsunawaki S, Nathan CF: Enzymatic basis of macrophage activation. Kinetic analysis of superoxide production in lysates of resident and activated mouse peritoneal macrophages and granulocytes. J Biol Chem 1984, 259:4305-4312.

26. Bao $Y$, Kim E, Bhosle S, Mehta H, Cho S: A role for spleen monocytes in post-ischemic brain inflammation and injury. J Neuroinflammation 2010, 7:92.

27. Swirski FK, Libby P, Aikawa E, Alcaide P, Luscinskas FW, Weissleder R, Pittet MJ: Ly-6Chi monocytes dominate hypercholesterolemia-associated monocytosis and give rise to macrophages in atheromata. J Clin Invest 2007, 117:195-205

28. Swirski FK, Nahrendorf $M$, Etzrodt $M$, Wildgruber $M$, Cortez-Retamozo V, Panizzi P, Figueiredo JL, Kohler RH, Chudnovskiy A, Waterman P, Aikawa E, Mempel TR, Libby P, Weissleder R, Pittet MJ: Identification of splenic reservoir monocytes and their deployment to inflammatory sites. Science 2009, 325:612-616.

29. Kim E, Febbraio M, Bao Y, Tolhurst AT, Epstein JM, Cho S: CD36 in the periphery and brain synergizes in stroke injury in hyperlipidemia. Ann Neurol 2012, 71:753-764

30. Lin TN, He YY, Wu G, Khan M, Hsu CY: Effect of brain edema on infarct volume in a focal cerebral ischemia model in rats. Stroke 1993, 24:117-121.

31. Bates SH, Stearns WH, Dundon TA, Schubert M, Tso AW, Wang Y, Banks AS, Lavery HJ, Haq AK, Maratos-Flier E, Neel BG, Schwartz MW, Myers MG Jr: STAT3 signalling is required for leptin regulation of energy balance but not reproduction. Nature 2003, 421:856-859.

32. Kondo $T$, Kahn CR: Altered insulin signaling in retinal tissue in diabetic states. J Biol Chem 2004, 279:37997-38006.

33. Orland MJ, Permutt MA: Quantitative analysis of pancreatic proinsulin mRNA in genetically diabetic (db/db) mice. Diabetes 1987, 36:341-347.

34. Folbergrova J, Memezawa H, Smith ML, Siesjo BK: Focal and perifocal changes in tissue energy state during middle cerebral artery occlusion in normo- and hyperglycemic rats. J Cereb Blood Flow Metab 1992, 12:25-33.

35. Hoxworth JM, Xu K, Zhou Y, Lust WD, LaManna JC: Cerebral metabolic profile, selective neuron loss, and survival of acute and chronic hyperglycemic rats following cardiac arrest and resuscitation. Brain Res 1999, 821:467-479.

36. Siesjo BK: Mechanisms of ischemic brain damage. Crit Care Med 1988, 16:954-963.

37. Nedergaard M, Diemer NH: Focal ischemia of the rat brain, with special reference to the influence of plasma glucose concentration. Acta Neuropathol 1987, 73:131-137.

38. Nedergaard M, Jakobsen J, Diemer NH: Autoradiographic determination of cerebral glucose content, blood flow, and glucose utilization in focal ischemia of the rat brain: influence of the plasma glucose concentration. J Cereb Blood Flow Metab 1988, 8:100-108.

39. Vannucci SJ, Willing LB, Goto S, Alkayed NJ, Brucklacher RM, Wood TL, Towfighi J, Hurn PD, Simpson IA: Experimental stroke in the female diabetic, db/db, mouse. J Cereb Blood Flow Metab 2001, 21:52-60.

40. Alvarez-Rodriguez L, Lopez-Hoyos M, Calvo-Alen J, Aurrecoechea E, Villa I, Martinez-Taboada VM: Phagocyte dysfunction in polymyalgia rheumatica and other age-related, chronic, inflammatory conditions. J Leukoc Biol 2013, 94:1071-1078.

41. Kumari R, Willing LB, Krady JK, Vannucci SJ, Simpson IA: Impaired wound healing after cerebral hypoxia-ischemia in the diabetic mouse. J Cereb Blood Flow Metab 2007, 27:710-718.

42. Ilyas R, Wallis R, Soilleux EJ, Townsend P, Zehnder D, Tan BK, Sim RB, Lehnert H, Randeva HS, Mitchell DA: High glucose disrupts oligosaccharide recognition function via competitive inhibition: a potential mechanism for immune dysregulation in diabetes mellitus. Immunobiology 2011, 216:126-131.

43. Kumari R, Willing LB, Patel SD, Krady JK, Zavadoski WJ, Gibbs EM, Vannucci SJ, Simpson IA: The PPAR-gamma agonist, darglitazone, restores acute inflammatory responses to cerebral hypoxia-ischemia in the diabetic ob/ob mouse. J Cereb Blood Flow Metab 2010, 30:352-360.

44. Martins JO, Ferracini M, Anger DB, Martins DO, Ribeiro LF Jr, Sannomiya P, Jancar S: Signaling pathways and mediators in LPS-induced lung inflammation in diabetic rats: role of insulin. Shock 2010, 33:76-82.

45. Martins JO, Zanoni FL, Martins DO, Coimbra R, Krieger JE, Jancar S, Sannomiya P: Insulin regulates cytokines and intercellular adhesion molecule-1 gene expression through nuclear factor-kappaB activation in LPS-induced acute lung injury in rats. Shock 2009, 31:404-409.

46. Cho S, Park EM, Febbraio M, Anrather J, Park L, Racchumi G, Silverstein RL, ladecola C: The class B scavenger receptor CD36 mediates free radical production and tissue injury in cerebral ischemia. J Neurosci 2005, 25:2504-2512

47. Alkhatatbeh MJ, Mhaidat NM, Enjeti AK, Lincz LF, Thorne RF: The putative diabetic plasma marker, soluble CD36, is non-cleaved, non-soluble and entirely associated with microparticles. J Thromb Haemost 2011, 9:844-851.

48. Bruno A, Qualls C: Risk factors for intracerebral and subarachnoid hemorrhage among Hispanics and non-Hispanic whites in a New Mexico community. Neuroepidemiology 2000, 19:227-232.

49. Eugenin EA, D'Aversa TG, Lopez L, Calderon TM, Berman JW: MCP-1 (CCL2) protects human neurons and astrocytes from NMDA or HIV-tat-induced apoptosis. J Neurochem 2003, 85:1299-1311.

50. Madrigal JL, Leza JC, Polak P, Kalinin S, Feinstein DL: Astrocyte-derived MCP-1 mediates neuroprotective effects of noradrenaline. J Neurosci 2009, 29:263-267.

51. DiPietro LA, Polverini PJ, Rahbe SM, Kovacs EJ: Modulation of JE/MCP-1 expression in dermal wound repair. Am J Pathol 1995, 146:868-875.

52. Low QE, Drugea IA, Duffner LA, Quinn DG, Cook DN, Rollins BJ, Kovacs EJ, DiPietro LA: Wound healing in MIP-1alpha(-/-) and MCP-1(-/-) mice. Am J Pathol 2001, 159:457-463.

\section{doi:10.1186/1742-2094-11-83}

Cite this article as: Kim et al:: Deregulation of inflammatory response in the diabetic condition is associated with increased ischemic brain injury. Journal of Neuroinflammation 2014 11:83.

\section{Submit your next manuscript to BioMed Central and take full advantage of:}

- Convenient online submission

- Thorough peer review

- No space constraints or color figure charges

- Immediate publication on acceptance

- Inclusion in PubMed, CAS, Scopus and Google Scholar

- Research which is freely available for redistribution 